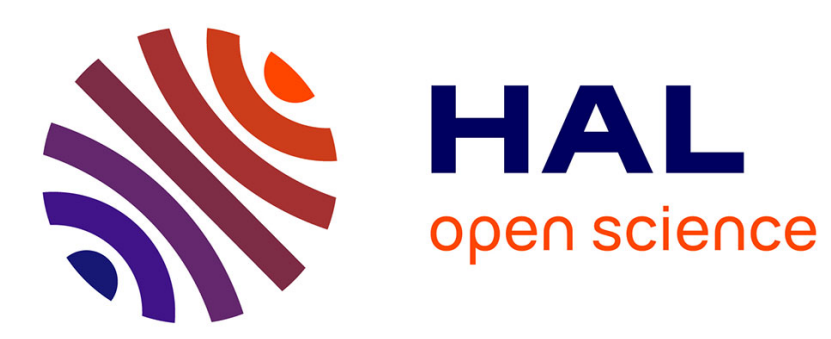

\title{
Simulation of Epitaxial Silicon Chemical Vapor Deposition in Barrel Reactors
}

\author{
M. Masi, S. Fogliani, S. Carrà
}

\section{To cite this version:}

M. Masi, S. Fogliani, S. Carrà. Simulation of Epitaxial Silicon Chemical Vapor Deposition in Barrel Reactors. Journal de Physique IV Proceedings, 1995, 05 (C5), pp.C5-261-C5-268. 10.1051/jphyscol:1995530 . jpa-00253855

\section{HAL Id: jpa-00253855 https://hal.science/jpa-00253855}

Submitted on 1 Jan 1995

HAL is a multi-disciplinary open access archive for the deposit and dissemination of scientific research documents, whether they are published or not. The documents may come from teaching and research institutions in France or abroad, or from public or private research centers.
L'archive ouverte pluridisciplinaire HAL, est destinée au dépôt et à la diffusion de documents scientifiques de niveau recherche, publiés ou non, émanant des établissements d'enseignement et de recherche français ou étrangers, des laboratoires publics ou privés. 


\title{
Simulation of Epitaxial Silicon Chemical Vapor Deposition in Barrel Reactors
}

\author{
M. Masi, S. Fogliani and S. Carrà \\ Dipartimento di Chimica Applicata - Politecnico di Milano, Piazza Leonardo da Vinci 32, 20133 Milano, \\ Italy
}

\begin{abstract}
SiCl}_{4} / \mathrm{H}_{2}$ mixtures in a $\mathrm{LPE} 861$ barrel reactor has been simulated by means of a detailed 2D model solved by the commercial finite element code FIDAP. Different reactor configurations (i.e., bell diameter, gas diffusors, susceptor tilting angle) and deposition conditions (i.e., flow rates and reactor pressure) have been examined. The simulation have been satisfactorily compared with experimental growth rate data measured along the reactor axial coordinate.
\end{abstract}

\section{INTRODUCTION AND AIMS}

The epitaxial deposition of silicon is an essential process of the VLSI technology and it is also becoming important in the fabrication of new MOS devices. Usually, such a deposition is obtained by cold wall CVD reactors operating with silane or chlorosilanes diluted in hydrogen. The reactors operate at nearly atmospheric or at reduced pressure and with temperature ranging about from the $400 \mathrm{~K}$ of the external wall to the $1400 \mathrm{~K}$ of the susceptor [1,2]. Such a high temperature gradient affects the system flow dynamics that result in a mixed flow regime (i.e., natural and forced convection) [3]. Previous investigations demonstrated that, in the conditions above, the deposition is under mass transport control and it is strongly influenced by the thermal diffusion effects [3]. Accordingly, the performances of those reactors and, particularly the uniformity of the thickness of the deposited film, are heavily influenced by their flow dynamic regime.

Among the different high productivity deposition reactors, it is very interesting to consider the barrel reactor, where a prismatic hot susceptor is contained in a quartz bell-jar externally cooled by air. Usually, the susceptor has a hexagonal or an octagonal base, and it is heated through radio frequency coils or with lamps. The barrel reactors usually are able to process from 12 to 24 wafers at time, depending on the susceptor geometry and loading. Unfortunately, such a high productivity is associated to film thickness uniformity control problems, both within the single wafer and among the wafers. Commercially different reactor configurations exist, being their main differences in the bell-jar shape and in the gas inlet apparatus.

As a first approximation, the study of such a reactors can be performed through simplified monodimensional models that describe the reactor flow dynamics by means of relationships based upon the boundary layer theory [4-6]. In fact, neglecting the inlet zone, the flow geometry of one barrel side resembles that of a horizontal reactor. Obviously, this similarity have to be corrected considering proper boundary layer relationships to account for susceptor rotation and buoyancy effects [6]. Unfortunately, the level of optimization required by the today microelectronics applications cannot be met with the previous approach. Accordingly, the barrel reactor optimization and design can be performed only through models where the geometry and the reactor flow dynamics were accounted in detail [3]. Considering their geometric complexity only a few modeling attempts were present in the literature. In 
fact, due to the prismatic shape of the susceptor, the system geometry is intrinsically 3D. Furthermore the gas motion in the inlet zone has a strong influence on the deposition profile $[7,8]$. The first 2D mode of a barrel reactor was presented by Fujii et al. [9], neglecting the inlet zone and the thermal diffusia: effects. The thermal diffusion effect was included in the 2D analysis by Juza and Cermak [10], sti]! neglecting the effect of the inlet zone. A 2D axial-symmetric barrel reactor model for GaAs MOCVD small scale reactor was presented by Dilawari et al. [11] still considering a simplified inlet nozzle. A 3D flow dynamics in a 2D axial-symmetric system was presented by Yang et al. [12] to consider th: asymmetries of the gas inlet apparatus in their system. In most of the above cases [9-11] a comparisan with experimental growth rate data was also presented.

In this work, the epitaxial silicon deposition by $\mathrm{SiCl}_{4} / \mathrm{H}_{2}$ mixtures in a LPE 861 barrel reactor will be analyzed through a detailed model where a $3 D$ flow dynamic is solved in a $2 D$ axial-symmetris geometry. Initially, the model prediction will be compared with experimental growth rate profiles and lately some variation of the reactor operating conditions and configuration will be presented to test their effect on the reactor performances. The role of the gas inlet apparatus on the deposition profile will be particularly addressed. The considered reactor geometry is sketched in Figure 1, while its geometrical characteristics are summarized in Table 1.

Table 1: Geometrical characteristic of the LPE 861 barrel reactor

Tilt angle of the susceptor

Inlet side of the susceptor

Susceptor temperature

Internal diameter of the bell-jar

Wall temperature of the bell-jar

Rotation speed of the susceptor

$3^{\circ}$
$0.14 \mathrm{~m}$
$1473 \mathrm{~K}$
$0.335 \mathrm{~m}$
$460 \mathrm{~K}$
$0.52 \mathrm{rad} / \mathrm{s}$

$3^{\circ}$
Number of faces of the susceptor

Susceptor length

Wafer diameter

Wall thickness of the bell-jar

Internal diameter of the RF coil

Cooling air flow rate
6

$0.45 \mathrm{~m}$

$0.127 \mathrm{~m}$

$0.003 \mathrm{~m}$

$0.38 \mathrm{~m}$

$0.5 \mathrm{~m}^{3} / \mathrm{s}$

\section{MODELING}

The model involved the continuity, the momentum and the energy conservation equations together with the mass conservation equation for the deposition precursor. The equations were derived, in steady-state conditions and under axial symmetry, from those reported by Jensen in [3]. Here, all the three flow velocity components were considered for the momentum conservation equation (i.e., the axial, the radial and the azimuthal ones). The axisymmetric assumption was limited to the reactor geometric representation. In fact, the true hexagonal susceptor base was approximated to a circular one whose diameter was chosen equal to the distance between the two opposite faces. Because the considered system operates in diluted conditions the simpler Fick law for the mass flux was adopted instead that the detailed Stefan-Maxwell equation. Considering the important role of the thermal diffusion effect, such a contribution was included in the expression of the mass flux. Here, a constant thermal diffusion factor was considered, due to the limits of the commercial finite element code adopted for the solution of the model ( $\alpha_{\mathrm{T}}=1.34$ ). Furthermore, the mass transport of the reactants from the bulk gas phase to the deposition surface was assumed to be the rate determining step of the process $[3,6]$. Accordingly, the precursor gas phase kinetics was neglected and only the surface reaction $\mathrm{SiCl}_{4}+\mathrm{H}_{2} \Leftrightarrow \mathrm{Si}_{(\mathrm{s})}+4 \mathrm{HCl}$ at chemical equilibrium was considered. On the thermal side of the model, a simplified fournace, with constant susceptor temperature was considered. The external bell-jar temperature value was estimated through the model reported in [6], whose heat exchange mechanism is represented in Figure 2 . In particular a linear profile was considered in the top part of the bell, while a constant temperature wals considered for the cylindrical part of the quartz bell. Furthermore, due to the low conversion of the 
reactor, the contribution of the heat of reaction and of the heat generated by viscous dissipation to the energy balance was neglected. The obtained PDE system was solved through the commercial finite elements code FIDAP [13]. The adopted chemico-physical parameter are summarized in Table 2, being all the values obtained from literature compilations $[4,14]$.

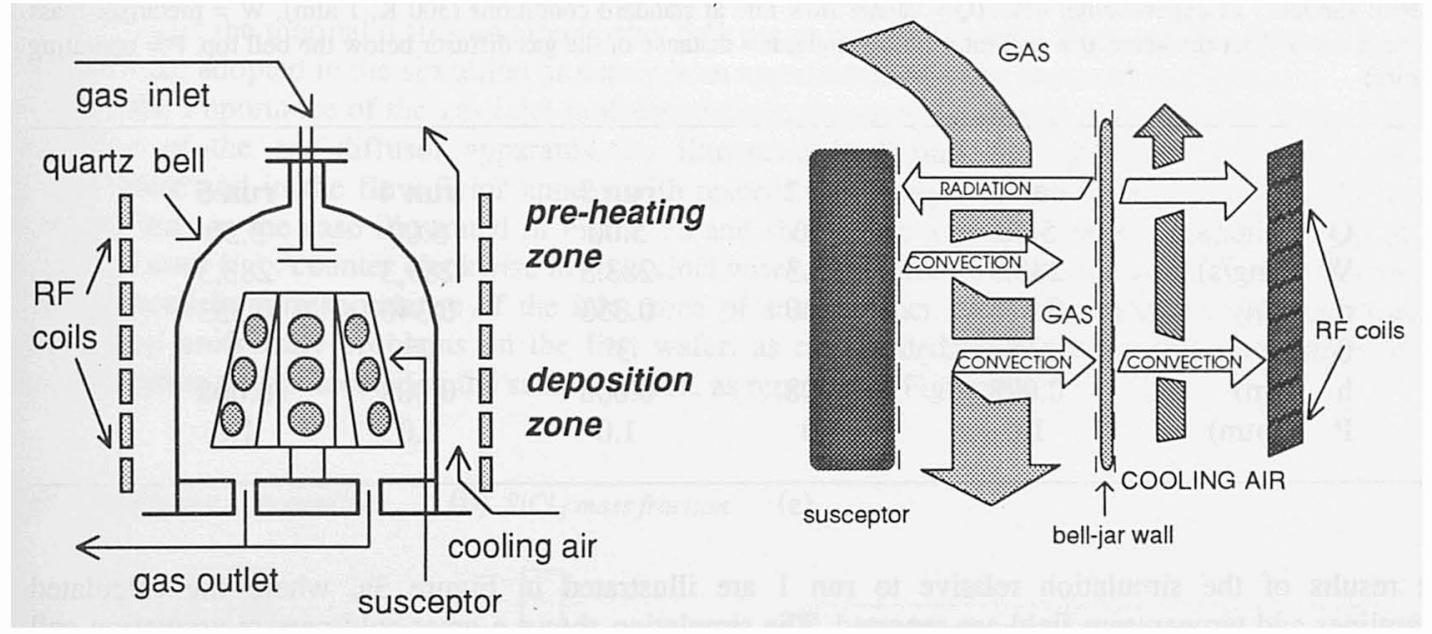

Figure 1: Schematic of the cold wall barrel reactor.

Figure 2: Schematic of the heat exchange mechanism in the barrel reactor.

Table 2: Summary of the adopted physico-chemical properties ( $\mathrm{T}$ in $\mathrm{K}, \mathrm{P}$ in atm, $\mathrm{T}_{0}=300 \mathrm{~K}, \mathrm{P}_{0}=1 \mathrm{~atm}$ )

\section{Carrier gas}

thermal conductivity, $\mathrm{k}_{\mathrm{T}}$

$$
\begin{aligned}
& =0.183\left(\mathrm{~T} / \mathrm{T}_{0}\right)^{0.710} \\
& =89.610^{-7}\left(\mathrm{~T} / \mathrm{T}_{0}\right)^{0.678} \\
& =14.31\left(\mathrm{~T} / \mathrm{T}_{0}\right)^{0.678}
\end{aligned}
$$

viscosity, $\mu$

specific heat, $\mathrm{Cp}$

$\mathrm{W} / \mathrm{m} \mathrm{K}$

$\mathrm{N} s / \mathrm{m}^{2}$

$\mathrm{kJ} / \mathrm{kg} \mathrm{K}$

\section{$\mathrm{SiCl}_{4}$}

$$
\begin{array}{ll}
\text { Binary diffusion coefficient, } \mathrm{D}_{\mathrm{i}} & =3.3210^{-7}(1 / \mathrm{P})\left(\mathrm{T} / \mathrm{T}_{0}\right)^{1.735} \\
\text { Thermal diffusion factor, } \alpha_{\mathrm{T}} & =0.484+0.408\left(\mathrm{~T} / \mathrm{T}_{0}\right)-0.044\left(\mathrm{~T} / \mathrm{T}_{0}\right)^{2}
\end{array}
$$

\section{RESULTS}

A suitable set of experimental data was produced to test the model reliability [6]. The operating conditions of the five experimental runs were summarized in Table 3 . The effects of the bell diameter, of the susceptor tilting and of the carrier flow rate were analyzed. In all cases the inlet gas temperature was $300 \mathrm{~K}$ and the operating pressure was atmospheric. The cooling air temperature was measured in correspondence of the inlet and the outlet sections. No significant variations were recorded among the considered five experimental runs and those values were $311 \mathrm{~K}$ and $410 \mathrm{~K}$, respectively. In all cases, the susceptor temperature was set to $1473 \mathrm{~K}$ and no significant temperature differences were revealed along the susceptor. Using a simplified model [6] an internal wall temperature of $460 \mathrm{~K}$ was estimateci for the 
cylindrical part of the bell. For these runs, the reactor was equipped with a gas diffusor of cylindrical shape that injects the gases radially. The gas diffusor was constituted by two quartz disks, $8.0 \mathrm{~cm}$ in diameter, separated by $1.0 \mathrm{~cm}$.

Table 3: summary of experimental runs. $(Q=$ carrier flow rate at standard conditions $(300 \mathrm{~K}, 1 \mathrm{~atm}), \mathrm{W}=$ precursor mass flow rate, $d=$ bell-jar diameter, $\theta=$ susceptor tilting angle, $h=$ distance of the gas diffusor below the bell top, $P=$ operating pressure)

The results of the simulation relative to run 1 are illustrated in Figure $3 \mathrm{a}$, where the calculated streamlines and temperature field are reported. The simulation shows a great cold-core recirculation cell above the susceptor, similar to that presented by the vertical CVD reactors [15]. The recirculation cell is generated not only by the combination of the buoyancy forces and of the susceptor rotation, but also by the radially directed inlet gas velocity. Besides this recirculation cell, part of the gases enter the annular duct still not well heated, generating a phenomena similar to the "cold finger" one, typical of the horizontal reactors $[3,16]$. The recirculation cell shows almost the inlet precursor concentration, being all the concentration gradients localized in correspondence of the susceptor area holding the wafers, as sketched in Figure $3 b$.

(a) temperature - streamlines

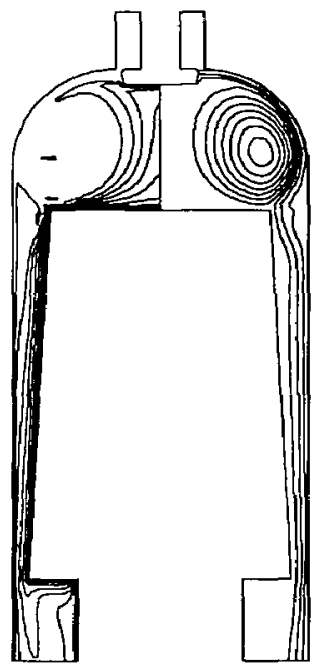

(b) $\mathrm{SiCl}_{4}$ mass fraction

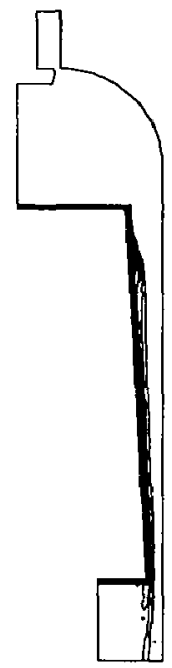

(c)

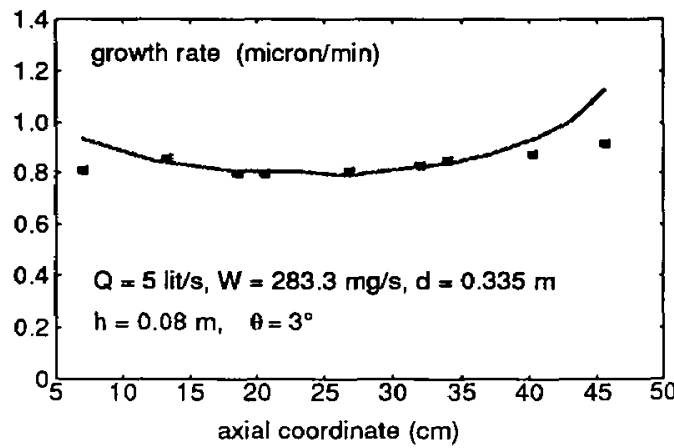

Figure 3: Simulation for run 1 of Table 3. (a) calculated strcamlines (left), temperature field (right); (b) calculated $\mathrm{SiCl}_{4}$ mass fraction: (c) comparison of calculated (-) and expcrimental (***) growth rate data along the wafer midline. 
In Figure $3 \mathrm{c}$ also the comparison between the calculated and experimental growth rate data measured along the longitudinal wafers midline is reported. Recalling that no adjustable parameters were used, a satisfactory agreement between the simulation and the experiment is observed. The deviation of the calculations with respect the experiments in correspondence of the final part of the susceptor can be correlated to the constant value of the thermal diffusivity factor here adopted. In fact, the lower part of the susceptor is characterized by the higher value of the temperature gradient in the gas phase. Accordingly, the thermal diffusion effects play they major role in this area. Furthermore, the constant bell temperature adopted in the simultion probably is an approximation to be removed in the future.

To test the importance of the gas inlet in these systems, the same simulation was repeated neglecting the presence of the gas diffusor apparatus. As illustrated in Figure 4a, significant differences in the temperature and in the flow fields appear with respect the previous case. The recirculation cell is less marked than in the case illustrated in Figure $3 \mathrm{a}$ and shows also a rotation sense contrary to that of the previous case (i.e., counter clockwise instead clockwise). Furthermore a second smaller recirculation cell is evidenced in correspondence of the inlet zone of annular duct. Obviously, this presence can lead in deposition uniformity problems on the first wafer, as can be deducted also by the observation of the concentration vortex located in the same position, as reported in Figure 4b.

(a)

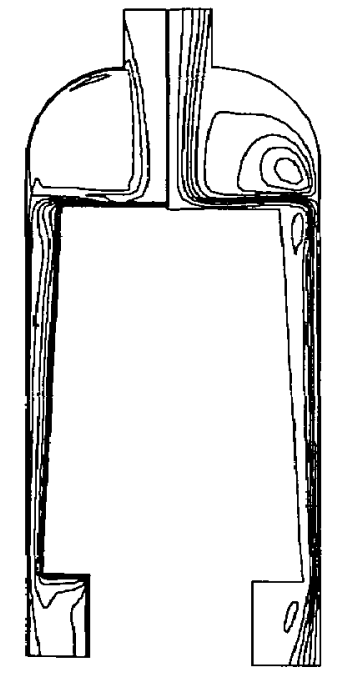

(b) $\mathrm{SiCl}_{4}$ mass fraction

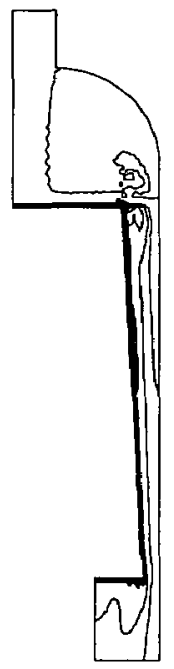

(c)

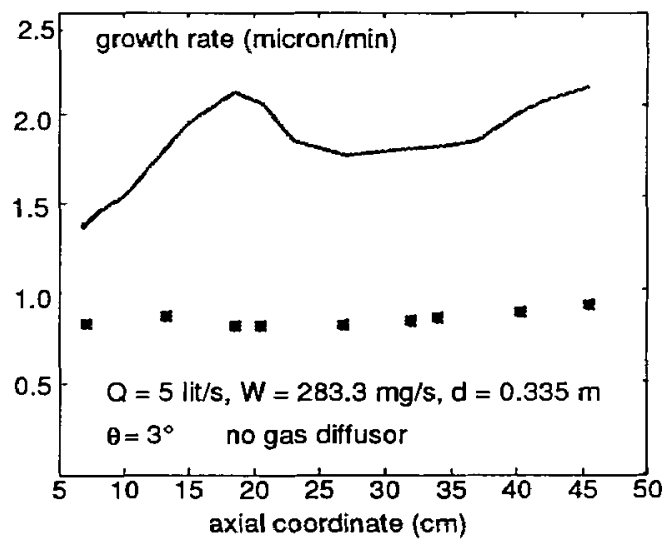

Figure 4: Simulation for run 1 of Table 3. (a) calculated streamlines (left), temperature field (right); (b) calculated $\mathrm{SiCl}_{4}$ mass fraction; (c) comparison of calculated $(-$ ) and experimental $(* * *)$ growth rate data along the wafer midline. Calculations performed neglecting the presence of the inlet gas diffusor.

The differences among the two simulations of run 1 are even greater when the comparison between the calculated and the experimental deposition profile is considered. As illustrated by Figure 4c, neglecting the presence of the gas inlet apparatus the calculated values of the growth rate data are off the experimental ones by almost the $100 \%$. The conclusion is that the presence of the gas diffusor apparatus cannot be neglected in these systems. Accordingly, also their shape and location will play a significant role in the reactor design and optimization. The results of the simulations of the remaining runs of Table 3 (i.e., runs 2-5) are illustrated in Figure 5, where the comparisons between the calculated and the experimental deposition profile are reported. The streamlines. the precursor distribution and the temperature field were not reported, because they are qualitatively similar to those of Figure 3 , besides the change in the reference values. 
(a)

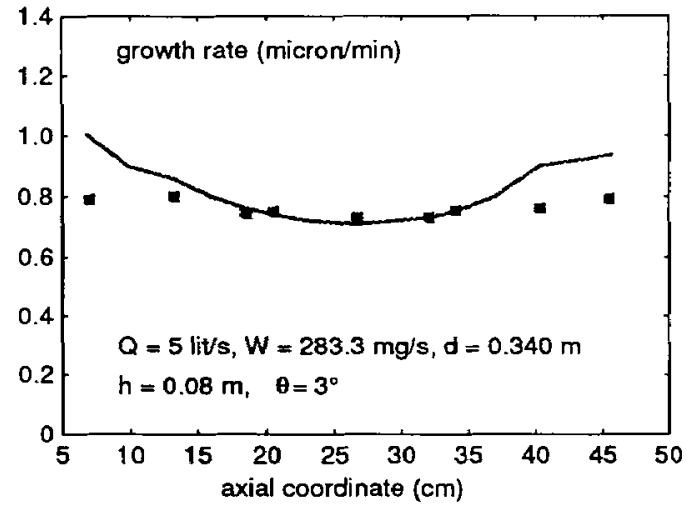

(c)

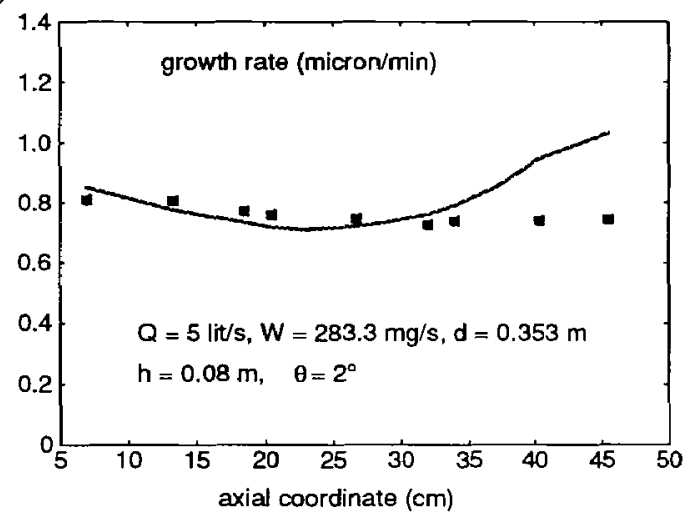

(b)

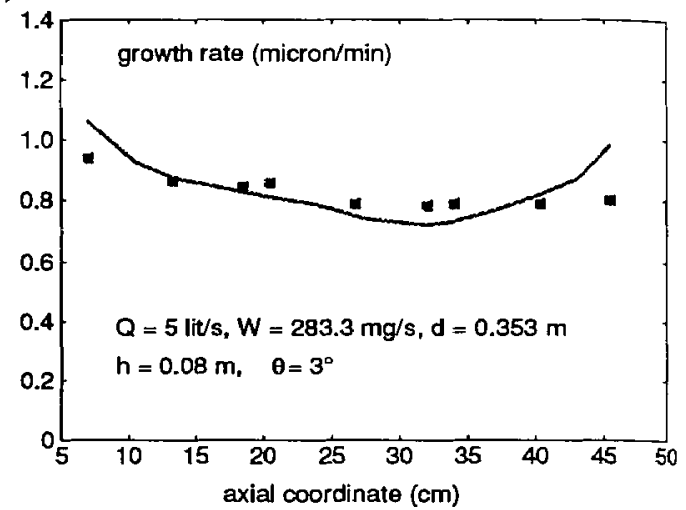

(d)

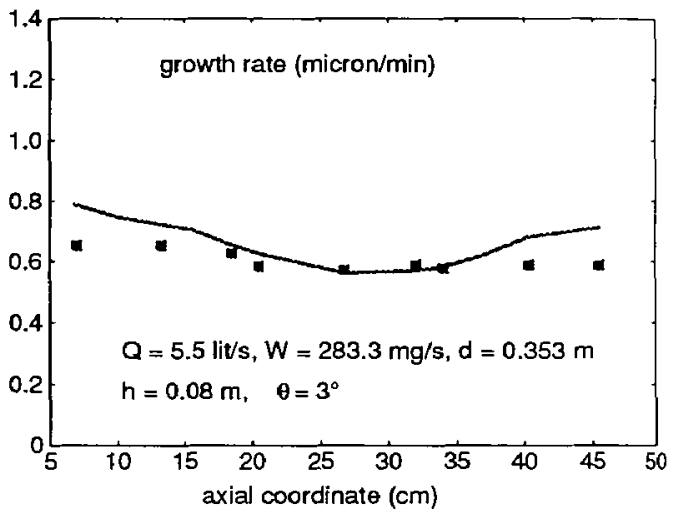

Figure 5: Comparison between calculated $(\longrightarrow)$ and experimental $(* * *)$ growth rate data along the wafer midline for runs 2-5 of Table 3. (a) run 2, (b) run 3, (c) run 4, (d) run 5.

The effect of the variation of the bell diameter can be discussed by the inspection of Figures $3 \mathrm{c}$, 5a and $5 \mathrm{~b}$. Increasing the bell diameter from $0.335 \mathrm{~m}$ to $0.340 \mathrm{~m}$, the increase of the free cross section decreases the gas flow rate and then the average growth rate, as expected for a mass transport controlled deposition. Surprisingly, an additional increase of the bell diameter (to $0.353 \mathrm{~m}$ ) increases the average growth rate. This apparently anomalous behavior is due to the role played by the thermal diffusion. Moreover, the decrease of the fluid velocity is compensated by the reduction of the temperature gradients that, accordingly, increases the mass flux towards the deposition surface. In fact, in these systems, the thermal diffusion has a negative contribution to the mass flux of the precursor towards the hot susceptor [17]. The effect of the variation of the tilt angle of the susceptor is illustrated by the comparison of the deposition profiles reported in Figures $5 \mathrm{a}$ and $5 \mathrm{c}$. A one degree reduction (from $3^{\circ}$ to $2^{\circ}$ ) produces an increase of the uniformity of the deposition profile in correspondence of the first wafer. This effect can be correlated to the smoother variation of the gas flow rate along the susceptor. Finally, the effect of the precursor dilution can be observed by the comparison of Figures $5 \mathrm{~b}$ and $5 \mathrm{~d}$. The precursor dilution was here obtained by an increase of the carrier flow rate. A $25 \%$ decrease of the average deposition rate is observed (from about $0.8 \mu \mathrm{m} / \mathrm{min}$ to about $0.6 \mu \mathrm{m} / \mathrm{min}$ ) when the precursor concentration is reduced by the $6 \%$. This apparent enhancement of the decrease of the growth rate average value is due to the correspondent average residence time of the precursor within the reactor, due to the increased carrier flow rate. The runs above demonstrate that an optimization of the tilting of the susceptor and of the gas free 
cross-section minimize the depletion of the precursor along the flow direction, just as a horizontal reactor.

In conclusion, the simulations show a satisfactory agreement with the experiments in all the cases examined above. Accordingly the model can be adopted to simulate operating conditions not previously examined experimentally, in particular the role of the gas distribution in the inlet zone, not accounted in the previous analysis.

Following the Fotiadis et al. [15] analysis on a vertical MOCVD reactor, a reduced pressure deposition was then analyzed. The operation at reduced pressure is expected to improve the deposition uniformity not only for vertical CVD reactors but also for barrel ones [18,19]. Accordingly, run 1 of Table 3 was reconsidered, changing the operating pressure value to $0.3 \mathrm{~atm}$. The results of the simulation are illustrated in Figure 6. The streamlines reported in Figure 6a seems to be very similar to those of Figure 3a, but it should be noted that the inlet gas velocity was about $11.0 \mathrm{~cm} / \mathrm{s}$ instead then about $3.0 \mathrm{~cm} / \mathrm{s}$. Accordingly, the effect of the buoyancy driven flows is significantly less important with respect to the forced ones. The decrease of the gas density reduces also the temperature gradient in the proximity of the susceptor and the mass transport resistances. Correspondingly, an increase of the average growth rate value was observed.

(a) temperature - streamlines

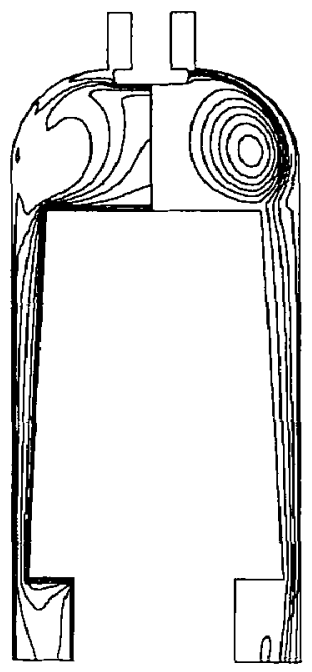

(b) $\mathrm{SiCl}_{4}$ mass fraction

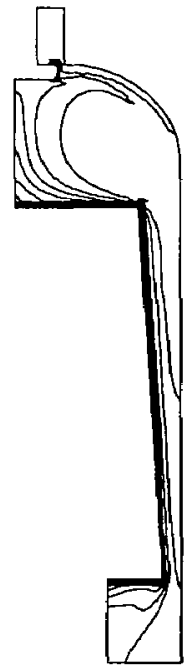

(c)

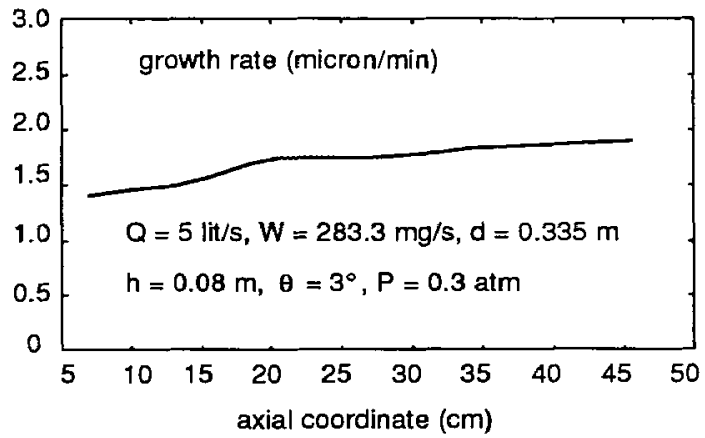

Figure 6: Simulation for run 1 of Table 3 with an operating pressure of $0.3 \mathrm{~atm}$. (a) calculated streamlines (left), temperature field (right); (b) calculated $\mathrm{SiCl}_{4}$ mass fraction; (c) comparison of calculated $(\longrightarrow)$ and experimental (***) growth rate data along the wafer midline.

Unfortunately, the operative conditions here considered do not enhance the uniformity of the deposition profile as originally expected. In the particular case here considered, the reduced uniformity of the deposition profile can be correlated to the higher concentration gradient along the susceptor longitudinal coordinate with respect to the one of the reference case. Correspondingly, the optimization of the barrel reactors is not trivial. Several simulations have to be performed to find the geometry and the operating conditions that increase the uniformity of the deposition profile on susceptors in the half a meter scale. 


\section{CONCLUSIONS}

A theoretical analysis of the silicon epitaxial deposition in a LPE 861 barrel reactor was presented, where a 3D flow dynamic in a $2 \mathrm{D}$ axisymmetric reactor geometry was considered. The model was able to predict the experimental trends without the use of adjustable parameters within the $20 \%$. A lower uniformity of the depostion profile was systematically evidenced by the reported simulations with respect the experimental data. Such a deviation can be related both to the constant values of the thermal diffusion factor and of the wall temperature here adopted. In any case, also with the above limitations, the reliability of the mathematical modeling of such systems was then confirmed. Thus, models can be safely adopted in designing and optimizing these systems. Some cautions, as usual, must be taken when the model is adopted outside the field of verification. In fact, it was developed under mass transport rate determining step regime and then the chemical kinetics did not play any role. That can be misleading in the case where a dopant as arsine is added, whose effect is the blocking of some surface sites and then shifting the rate determining step to be the surface kinetics instead that the mass transport. Some other cautions should be placed to the 2D reduction of the geometry and to the axisymmetric hypothesis. Previous work indicates that even slightly deviation from this condition could have a major effect on the performance of the system.

\section{Acknowledgments}

The autors are grateful to the Italian Ministero dell'Università e della Ricerca Scientifica e Tecnologica (MURST 40\%) for the financial support.

\section{References}

[1] Sze S.M. (ed), VLSI Technology (McGraw-Hill, New York, 1983).

[2] Jensen K.F. and Kern W., Thin Film Process II (eds.: Vossen J.L. and Kern W., Academic Press, San Diego CA, 1991) pp. 283-368.

[3] Jensen K.F., Chemical Vapor Deposition: Principles and Applications (eds.: Hitchman M.L. and Jensen K.F., Academic Press, London UK, 1993) pp. 31-90.

[4] Manke C.W. and Donaghey L.F., J. Electrochem. Soc. 124 (1977) 561-569.

[5] Dittman F.W., Adv. Chem. Serv. 133 (1979) 463-473.

[6] Masi M., S. Carrà, Morbidelli M., Scaravaggi V. and Preti F., Chem. Eng. Sci. 45 (1990) 3551. 3561.

[7] Lord H.A., J. Electrochem. Soc. 134 (1987) 1227-1235.

[8] Corboy J.F. and Pagliaro R. Jr., RCA Review. 44 (1983) 231-249.

[9] Fujii E., Nakamura H., Haruna K. and Koga Y., J. Electrochem. Soc. 119 (1972) 1106-1113.

[10] Juza J. and Cermak J., J. Electrochem. Soc. 129 (1982) 1627-1634.

[11] Dilawari A.H., Szekely J. and Daly J., J. Crystal Growth 102 (1990) 635-642.

[12] Yang L., Farouk B. and Mahajan R.L., J. Electrochem. Soc. 139 (1992) 2666-2673.

[13] "Fidap theory manual", revision 7 (FDI inc., Evanston IL, 1993)

[14] Hunt L.P and Sirtl E., J. Electrochem. Soc. 119 (1972) 1741-1475.

[15] Fotiadis D.I., Kieda S. and Jensen K.F, J. Crystal Growth 102 (1990) 441-470.

[16] Fotiadis D.I., M. Boekholt M., Jensen K.F. and Richter W., J. Crystal Growth 102 (1990) 743-761.

[17] Jenkinson J.P. and Pollard R., J. Electrochem. Soc. 131 (1984) 2911-2917.

[18] Moon R.L. and Houng Y., Chemical Vapor Deposition: Principles and Applications (eds: Hitchman M.L. and Jensen K.F., Academic Press, London UK, 1993) pp. 245-384.

[19] Nakamura F. and Kawai H., J. Crystal Growth 93 (1988) 292-300. 